DOI: $10.21105 /$ joss. 03221

\title{
mosartwmpy: A Python implementation of the MOSART-WM coupled hydrologic routing and water management model
}

\author{
Travis Thurber ${ }^{1}$, Chris R. Vernon ${ }^{1}$, Ning Sun ${ }^{1}$, Sean W. D. Turner ${ }^{1}$, \\ Jim Yoon ${ }^{1}$, and Nathalie Voisin ${ }^{1}$
}

1 Pacific Northwest National Laboratory, Richland, WA., USA

\section{Software}

- Review ¿

- Repository ca

\section{Summary}

- Archive [x

Editor: Kristen Thyng ¿

Reviewers:

- CJannisHoch

- Qcheginit

Submitted: 08 April 2021

Published: 24 June 2021

\section{License}

Authors of papers retain copyright and release the work under a Creative Commons Attribution 4.0 International License (CC BY 4.0). mosartwmpy is a Python implementation of the Model for Scale Adaptive River Transport with Water Management (MOSART-WM). This new version retains the functionality of the legacy model (written in FORTRAN) while providing new features to enhance user experience and extensibility. MOSART is a large-scale river-routing model used to study riverine dynamics of water, energy, and biogeochemistry cycles across local, regional, and global scales (Li et al., 2013). The WM component introduced by Voisin et al. (2013) represents river regulation through reservoir storage and release operations, diversions from reservoir releases, and allocation to sectoral water demands. Each reservoir release is independently calibrated using long-term mean monthly inflow into the reservoir, long-term mean monthly demand associated with this reservoir, and reservoir goals (flood control, irrigation, recreation, etc.). Generic monthly pre-release rules and storage targets are set up for individual reservoirs; however, those releases are updated annually for inter-annual variability (dry or wet year) and daily for environmental constraints such as flow minimum release and minimum/maximum storage levels. The WM model allows an evaluation of the impact of water management over multiple river basins at once (global, continental scales) and with consistent representation of human operations over the full domain.

\section{Statement of Need}

MOSART-WM is often utilized as the hydrological component in a larger suite of earthscience models, such as in E3SM Project (2018). In this context, MOSART-WM is quite efficient and streamlined when running on a supported High-Performance Computing (HPC) cluster. However, learning how to use, extend, and test a complex codebase written with domain knowledge implied in a lower-level programming language may greatly increase the turnaround time and error rate for setting up and executing novel experiments. Broadening the code's accessibility using a programming language such as Python, which in 2020 was the second most utilized language on GitHub (GitHub, 2020), provides a more accessible option to learn and contribute to the science on most computational platforms.

mosartwmpy was designed to bridge the gap between the domain scientist who wants a performant software that can still be extended for future research needs, and the new user who may not have expertise within the hydrologic sciences but wishes to integrate the process into their own workflow or quickly become capable in conducting hands-on experimentation for educational purposes. A refactor of MOSART-WM in Python ameliorates the steep learning curve of the FORTRAN version by providing an easy to learn, use, and modify interface. 
mosartwmpy was also built with interoperability in mind by implementing the Community Surface Dynamics Modeling System (CSDMS) Basic Model Interface (BMI) (Hutton et al., 2020; Peckham et al., 2013), which offers a familiar set of controls for operating the model. By leveraging the BMI, mosartwmpy can be readily coupled with other earth system models to perform cross-domain experiments.

The target audience for mosartwmpy is the data scientist or hydrologist who wishes to rapidly prototype, test, and develop novel modeling capabilities relating to reservoirs and water demand. mosartwmpy can be accessed on GitHub (https://github.com/IMMM-SFA/ mosartwmpy), and a walkthrough of key functionality and use can be found here: tutorial. Model results have been validated against historical simulations (Turner, Doering, et al., 2020), and a validation utility is included with the code.

\section{State of the field}

In addition to mosartwmpy's ancestor MOSART-WM, several other models are commonly used in hydrologic modeling, each excelling at different processes. The Community Land Model (CLM; Lawrence et al., 2019) focuses on the traditional water cycle (i.e. precipitation, evaporation) as well as plant and soil chemistry; runoff output from CLM can be used as input for mosartwmpy. StateMod (CDSS, 2018) focuses on water allocation based on legal constraints (water rights) as well as supply and demand. MODFLOW (Langevin \& Panday, 2021) focuses on solving for complex groundwater flow properties on three-dimensional grids. GLOFRIM (Hoch et al., 2017) focuses on providing a framework to couple models implementing the BMI across multi-scale grids, for instance by coupling a meteorological model to a water cycle model to river routing model to hydrodynamic model. In this context, mosartwmpy focuses on the interactions between river routing, reservoir management, and water demand.

\section{Functionality}

Model input for mosartwmpy consists of channel and reservoir geometry, groundwater and subsurface runoff (i.e. rain and ice melt), and water demand. The runoff populates the local streams and river channels, which generally flow toward the oceans (as in Figure 1). In many locations along the main channels, reservoirs collect and store water, releasing portions of the storage downstream over time for various societal uses (i.e. hydroelectricity, drinking water, flood control, and irrigation). Water is also consumed directly from the channels and tributaries for irrigation or non-irrigation uses.

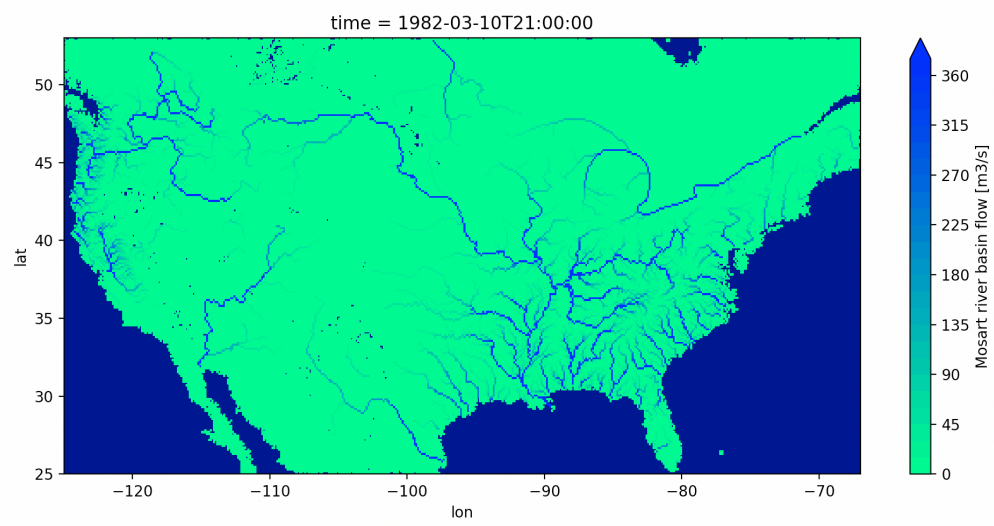

Figure 1: River basin flow over the continental United States as output from mosartwmpy.

Thurber et al., (2021). mosartwmpy: A Python implementation of the MOSART-WM coupled hydrologic routing and water management 2 model. Journal of Open Source Software, 6(62), 3221. https://doi.org/10.21105/joss.03221 


\section{Ongoing Research}

As open-source software, mosartwmpy promotes collaborative and community model development to meet scientific objectives. Two examples of the potential to extend this codebase are currently underway as a part of the U.S. DOE's Department of Energy's Integrated Multisector Multiscale Modeling (IM3) basic research project: an Agent Based Model (ABM) for more accurately simulating irrigation demand based on the economics of various crop types (Hyun et al., 2019; Yoon et al., 2021), and an improved reservoir operations module for more accurately simulating reservoir release based on data-driven harmonic functions (Turner, Xu, et al., 2020). Future planned experiments will study the uncertainty characterization and quantification (Chaney et al., 2015) of the model based on perturbations in key parameters.

\section{Acknowledgements}

This research was supported by the U.S. Department of Energy, Office of Science, as part of research in MultiSector Dynamics, Earth and Environmental System Modeling Program. The Pacific Northwest National Laboratory is operated for DOE by Battelle Memorial Institute under contract DE-AC05-76RL01830. The views and opinions expressed in this paper are those of the authors alone.

\section{References}

CDSS. (2018). StateMod-15.00.14. [Computer Software]. https://github.com/OpenCDSS/ cdss-app-statemod-fortran

Chaney, N. W., Herman, J. D., Reed, P. M., \& Wood, E. F. (2015). Flood and drought hydrologic monitoring: The role of model parameter uncertainty. Hydrology and Earth System Sciences, 19(7), 3239-3251. https://doi.org/10.5194/hess-19-3239-2015

E3SM Project, D. (2018). Energy Exascale Earth System Model v1.0. [Computer Software]. https://doi.org/10.11578/E3SM/dc.20180418.36

GitHub, Inc. (2020). In The State of the Octoverse. GitHub. https://octoverse.github.com/

Hoch, J. M., Neal, J. C., Baart, F., Beek, R. van, Winsemius, H. C., Bates, P. D., \& Bierkens, M. F. (2017). GLOFRIM v1.0-a globally applicable computational framework for integrated hydrological-hydrodynamic modelling. Geoscientific Model Development, 10(10), 3913-3929. https://doi.org/10.5194/gmd-10-3913-2017

Hutton, E. W. H., Piper, M. D., \& Tucker, G. E. (2020). The Basic Model Interface 2.0: A standard interface for coupling numerical models in the geosciences. Journal of Open Source Software, 5(51), 2317. https://doi.org/10.21105/joss.02317

Hyun, J.-Y., Huang, S.-Y., Yang, Y.-C., Tidwell, V., \& Macknick, J. (2019). Using a coupled agent-based modeling approach to analyze the role of risk perception in water management decisions. Hydrology and Earth System Sciences, 23, 2261-2278. https://doi.org/10. 5194/hess-23-2261-2019

Langevin, H., C. D., \& Panday, S. (2021). MODFLOW 6 Modular Hydrologic Model version 6.2.1. [Computer Software]. https://doi.org/10.5066/F76Q1VQV

Lawrence, D. M., Fisher, R. A., Koven, C. D., Oleson, K. W., Swenson, S. C., Bonan, G., Collier, N., Ghimire, B., Kampenhout, L. van, Kennedy, D., Kluzek, E., Lawrence, P. J., Li, F., Li, H., Lombardozzi, D., Riley, W. J., Sacks, W. J., Shi, M., Vertenstein, M., ... Zeng, X. (2019). The Community Land Model Version 5: Description of new features, 
benchmarking, and impact of forcing uncertainty. Journal of Advances in Modeling Earth Systems, 11(12), 4245-4287. https://doi.org/10.1029/2018MS001583

Li, H., Wigmosta, M. S., Wu, H., Huang, M., Ke, Y., Coleman, A. M., \& Leung, L. R. (2013). A physically based runoff routing model for land surface and Earth system models. Journal of Hydrometeorology, 14(3), 808-828. https://doi.org/10.1175/JHM-D-12-015.1

Peckham, S. D., Hutton, E. W., \& Norris, B. (2013). A component-based approach to integrated modeling in the geosciences: The design of CSDMS. Computers \& Geosciences, 53, 3-12. https://doi.org/10.1016/j.cageo.2012.04.002

Turner, S., Doering, K., \& Voisin, N. (2020). Data-driven reservoir simulation in a large-scale hydrological and water resource model. Water Resources Research, 56(10), e2020WR027902. https://doi.org/10.1029/2020WR027902

Turner, S., Xu, W., \& Voisin, N. (2020). Inferred inflow forecast horizons guiding reservoir release decisions across the United States. Hydrology and Earth System Sciences, 24, 1275-1291. https://doi.org/10.5194/hess-24-1275-2020

Voisin, N., Li, H., Ward, D., Huang, M., Wigmosta, M., \& Leung, L. (2013). On an improved sub-regional water resources management representation for integration into Earth system models. Hydrology \& Earth System Sciences, 17(9). https://doi.org/10.5194/ hess-17-3605-2013

Yoon, J., Klassert, C., Selby, P., Lachaut, T., Knox, S., Avisse, N., Harou, J., Tilmant, A., Klauer, B., Mustafa, D., Sigel, K., Talozi, S., Gawel, E., Medellín-Azuara, J., Bataineh, B., Zhang, H., \& Gorelick, S. M. (2021). A coupled human-natural system analysis of freshwater security under climate and population change. Proceedings of the National Academy of Sciences, 118(14). https://doi.org/10.1073/pnas.2020431118 